\title{
Article
}

\section{Highly Enhanced OER Performance by Er-Doped Fe-MOF Nanoarray at Large Current Densities}

\author{
Yan Ma ${ }^{1}$, Yujie Miao ${ }^{1}$, Guomei Mu ${ }^{1}$, Dunmin Lin ${ }^{1}$, Chenggang Xu ${ }^{1}$, Wen Zeng ${ }^{2}$ and Fengyu Xie ${ }^{1, *}$ \\ 1 College of Chemistry and Materials Science, Sichuan Normal University, No. 5, Jing'an Road, \\ Chengdu 610068, China; 20191201038@stu.sicnu.edu.cn (Y.M.); yujie@stu.sicnu.edu.cn (Y.M.); \\ guomei@stu.sicnu.edu.cn (G.M.); ddmd222@sicnu.edu.cn (D.L.); chenggangxu@163.com (C.X.) \\ 2 School of Chemistry and Chemical Engineering, Chongqing University, Shapingba District, \\ Chongqing 401331, China; wenzeng@cqu.edu.cn \\ * Correspondence: xiefengyu@sicnu.edu.cn
}

check for updates

Citation: Ma, Y.; Miao, Y.; Mu, G.; Lin, D.; Xu, C.; Zeng, W.; Xie, F.

Highly Enhanced OER Performance by Er-Doped Fe-MOF Nanoarray at Large Current Densities.

Nanomaterials 2021, 11, 1847. https:// doi.org/10.3390/nano11071847

Academic Editor: Namgee Jung

Received: 25 June 2021

Accepted: 12 July 2021

Published: 16 July 2021

Publisher's Note: MDPI stays neutral with regard to jurisdictional claims in published maps and institutional affiliations.

\begin{abstract}
Great expectations have been held for the electrochemical splitting of water for producing hydrogen as a significant carbon-neutral technology aimed at solving the global energy crisis and greenhouse gas issues. However, the oxygen evolution reaction (OER) process must be energetically catalyzed over a long period at high output, leading to challenges for efficient and stable processing of electrodes for practical purposes. Here, we first prepared Fe-MOF nanosheet arrays on nickel foam via rare-earth erbium doping $\left(\mathrm{Er}_{0.4} \mathrm{Fe}-\mathrm{MOF} / \mathrm{NF}\right)$ and applied them as OER electrocatalysts. $\mathrm{The} \mathrm{Er}_{0.4}$ Fe-MOF/NF exhibited wonderful OER performance and could yield a $100 \mathrm{~mA} \mathrm{~cm}^{-2}$ current density at an overpotential of $248 \mathrm{mV}$ with outstanding long-term electrochemical durability for at least $100 \mathrm{~h}$. At large current densities of 500 and $1000 \mathrm{~mA} \mathrm{~cm}^{-2}$, overpotentials of only $297 \mathrm{mV}$ and $326 \mathrm{mV}$ were achieved, respectively, revealing its potential in industrial applications. The enhancement was attributed to the synergistic effects of the Fe and Er sites, with Er playing a supporting role in the engineering of the electronic states of the Fe sites to endow them with enhanced OER activity. Such a strategy of engineering the OER activity of Fe-MOF via rare-earth ion doping paves a new avenue to design other MOF catalysts for industrial OER applications.
\end{abstract}

Keywords: rare-earth doping; MOFs; large current; electronic structure

\section{Introduction}

As a form of clean energy, hydrogen energy is of crucial importance in addressing the global energy crisis and greenhouse gas issues caused by increased consumption of fossil fuels sources. According to literature, water electrolysis technology is an effective method of obtaining high purity hydrogen and includes two half reactions: the cathodic hydrogen evolution reaction (HER) and anodic oxygen evolution reaction (OER). Compared with HER, the OER suffers from sluggish kinetics and thus requires higher energy input to overcome the reaction energy barrier [1-3]. Although $\mathrm{RuO}_{2}$ and $\mathrm{IrO}_{2}$ have been verified to be the most active OER catalysts, the high cost and scarcity of such catalysts restrict their large-scale application [4,5]. Thus, it is critical to find non-noble metals that have high activity, low cost, and are more stable at large currents for applications.

A great deal of research has been performed in order to investigate highly efficient non-noble metal-based OER catalysts, including metal oxides [6], chalcogenides [7,8], hydroxides [9], phosphides [10], nitrides [11], and metal organic frameworks (MOFs) [12-14]. Among them, MOFs exhibit superior OER activity. However, most reported MOF electrocatalysts have been evaluated in accordance with overpotentials and long-term stability under low current density, mostly less than $100 \mathrm{~mA} \mathrm{~cm}^{-2}$, and these assessment criteria are not realistic for industrial applications [15]. To be used for industrial applications, OER catalysts must deliver large-current-density $\left(500 \mathrm{~mA} \mathrm{~cm}^{-2}\right) \mathrm{OER}$ at low overpotentials. Accordingly, it is highly attractive to design and develop efficient OER electrocatalysts 
based on earth-abundant MOF alternatives at large current densities. Recent works have demonstrated modifying of the electronic structure of active sites by introducing foreign atoms as an effective strategy to enhance electrocatalysts' intrinsic activity. Specifically, Gao et al. systematically designed transition-metal-doped NiFe LDHs (using Co, Mn, and Cr metals). Combined with theory analysis, they found that the enhanced intrinsic OER activity was due to modifying the electronic structure of the intermediate site after Co, $\mathrm{Mn}$, and $\mathrm{Cr}$ doping [16]. Ma et al. proved that $\mathrm{Cu}$-doped $\mathrm{Ni}_{3} \mathrm{~S}_{2} / \mathrm{Co}_{3} \mathrm{~S}_{4}$ could not only increased the specific surface area but also alter the electron density of Ni/Co sites [17]. For the past few years, rare-earth elements have received more and more attention on account of the $4 \mathrm{f}$ orbitals partial filling [18,19]. Importantly, the doping of rare-earth elements can effectively regulate the electronic and geometric structures of electrocatalysts, thus improving their electrical conductivity and internal catalytic activity. For instance, Wan et al. synthesized La-doped $\operatorname{In}(\mathrm{OH})_{3}$, improving the visible light absorption capability for the photo-reduction of carbon dioxide [20]. Xu et al. reported that Ni-Fe-Ce-LDH microcapsules exhibited a high OER activity owing to the optimized electronic structure of 3D LDHs through Ce species doping [21]. Ahmad et al. found that doped Eu and Tb ions could enter the lattice of $\mathrm{ZnO}$, and the resulting $\mathrm{ZnO}$ had a large specific surface area and high porosity [22]. However, there still are few reports about enhancing the intrinsic OER activity of MOFs by rare-earth element doping, especially under large currents [23,24].

To tackle the above challenge, we rationally designed and synthesized Fe-MOF nanosheet arrays grown on 3D nickel foam (NF) via Er doping $\left(\mathrm{Er}_{0.4} \mathrm{Fe}-\mathrm{MOF} / \mathrm{NF}\right)$ as an advanced OER catalyst (Scheme 1). Comparing with the precursor Fe-MOF/NF, the achieved $\mathrm{Er}_{0.4} \mathrm{Fe}-\mathrm{MOF} / \mathrm{NF}$ exhibited an ultralow overpotential of $248 \mathrm{mV}$ to drive $100 \mathrm{~mA} \mathrm{~cm}^{-2}$ current density and showed an outstanding long-term electrochemical durability of more than $100 \mathrm{~h}$ without obvious decay. Moreover, the overpotentials of $297 \mathrm{mV}$ and $326 \mathrm{mV}$ were needed to drive 500 and $1000 \mathrm{~mA} \mathrm{~cm}^{-2}$, indicating its promising application. This work provides some inspiration for reasonably designing efficient and stable MOFs for industrial applications.

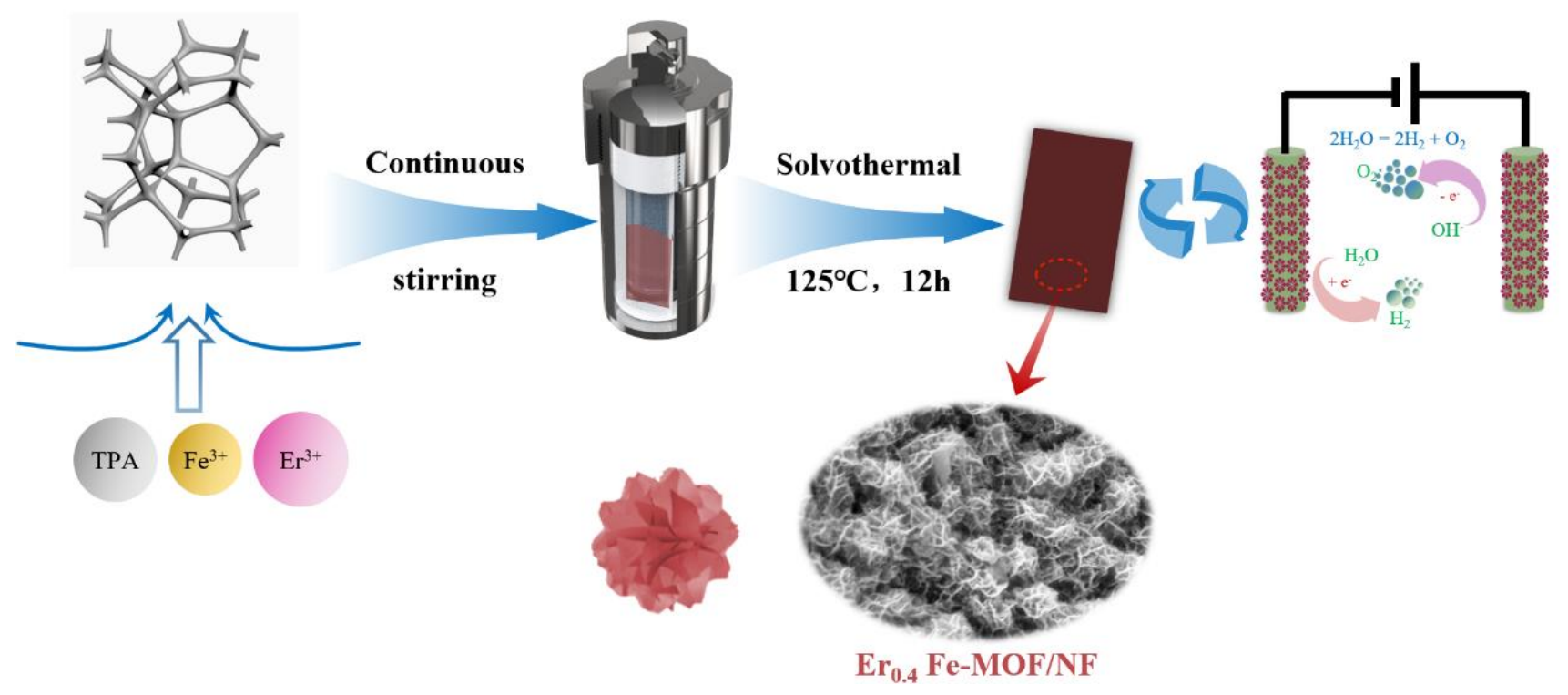

Scheme 1. Schematic illustrating the fabrication process for $\mathrm{Er}_{0.4} \mathrm{Fe}-\mathrm{MOF} / \mathrm{NF}$.

\section{Materials and Methods}

All chemical regents used in this work were analytically pure. Nickel foam (NF, area: $2 \mathrm{~cm} \times 3 \mathrm{~cm}$ ) was bought from Shenzhen Green and Creative Environmental Science and Technology Co., Ltd (Shenzhen, China). Ferric nitrate nonahydrate $\left(\mathrm{Fe}\left(\mathrm{NO}_{3}\right)_{3} \cdot 9 \mathrm{H}_{2} \mathrm{O}\right)$, erbium (III) nitrate hexahydrate $\left(\mathrm{Er}\left(\mathrm{NO}_{3}\right)_{3} \cdot 6 \mathrm{H}_{2} \mathrm{O}\right.$; Aladdin), terephthalic acid $\left(\mathrm{C}_{8} \mathrm{H}_{6} \mathrm{O}_{4}\right.$, 
TPA; Aladdin), hydrochloric acid (HCl; Aladdin), N, N-dimethylformamide (DMF; Beijing Chemical Industry Group Co., Ltd, Beijing China), ethanol, and deionized water were used.

\subsection{Preparation of $\mathrm{Er}_{0.4} \mathrm{Fe}-\mathrm{MOF}$ on $\mathrm{NF}$}

$\mathrm{Er}_{0.4} \mathrm{Fe}-\mathrm{MOF} / \mathrm{NF}$ was prepared via a one-step solvothermal method. First, $1 \mathrm{mmol}$ $\mathrm{Fe}\left(\mathrm{NO}_{3}\right)_{3} \cdot 9 \mathrm{H}_{2} \mathrm{O}(0.4040 \mathrm{~g}), 0.4 \mathrm{mmol} \mathrm{Er}\left(\mathrm{NO}_{3}\right)_{3} \cdot 6 \mathrm{H}_{2} \mathrm{O}(0.1845 \mathrm{~g})$, and $3 \mathrm{mmol}$ TPA $(0.4980 \mathrm{~g})$ were added to $35 \mathrm{~mL}$ of DMF while stirring uniformly at room temperature. Subsequently, $2.5 \mathrm{~mL}$ of ethanol and $2.5 \mathrm{~mL}$ of deionized water were added. This mixture was stirred vigorously for half an hour and rapidly transferred into a $50 \mathrm{~mL}$ autoclave. The treated $\mathrm{NF}(2 \times 3 \mathrm{~cm})$ was then placed in the homogeneous solution. The solution was put in one Teflon-lined stainless autoclave and reacted at $125^{\circ} \mathrm{C}$ for $12 \mathrm{~h}$. Finally, it was naturally cooled down to room temperature, the material was washed several times with deionized water, and it was dried in a vacuum oven at $60^{\circ} \mathrm{C}$. The mass loading of $\mathrm{Er}_{0.4} \mathrm{Fe}-\mathrm{MOF} / \mathrm{NF}$ was about $1.18 \mathrm{mg} \mathrm{cm}^{-2}$.

\subsection{Preparation of Fe-MOF on NF}

The Fe-MOF/NF was synthesized using the above-mentioned process without $\mathrm{Er}\left(\mathrm{NO}_{3}\right)_{3} \cdot 6 \mathrm{H}_{2} \mathrm{O}$ doping.

\subsection{Preparation of $\mathrm{RuO}_{2}$ on $\mathrm{NF}$}

$\mathrm{RuO}_{2} / \mathrm{NF}$ was prepared in accordance with the reported work. First, $2.61 \mathrm{~g}$ of $\mathrm{RuCl}_{3} \cdot 3 \mathrm{H}_{2} \mathrm{O}$ and $1.0 \mathrm{~mL} \mathrm{KOH}(1.0 \mathrm{M})$ were added into $100 \mathrm{~mL}$ of distilled water and stirred for $45 \mathrm{~min}$ at a temperature of $100{ }^{\circ} \mathrm{C}$. The precipitate was collected via centrifugation, washed several times with distilled water, and then dried in a vacuum oven at $60{ }^{\circ} \mathrm{C}$. Finally, the product was annealed at $300^{\circ} \mathrm{C}$ for $3 \mathrm{~h}$ in an air atmosphere to obtain $\mathrm{RuO}_{2}$ powder. Catalyst ink was prepared by dispersing $22.5 \mathrm{mg}$ of catalyst into $490 \mu \mathrm{L}$ of water/ethanol (volume ratio, $v / v=1: 1$ ) and $20 \mu \mathrm{L}$ of $5 \mathrm{wt} \%$ Nafion using sonication treatment for $30 \mathrm{~min}$. Subsequently, $13.0 \mu \mathrm{L}$ of the $\mathrm{RuO}_{2}$ ink (containing $0.295 \mathrm{mg}$ of $\mathrm{RuO}_{2}$ ) was loaded onto a bare NF of $0.25 \mathrm{~cm}^{-2}$ in geometric area (mass loading: $1.18 \mathrm{mg} \mathrm{cm}^{-2}$ ).

\subsection{Electrochemical Measurements}

All electrochemical tests were measured through using a $\mathrm{CHI} 660 \mathrm{E}$ electrochemical workstation (Shanghai Chenhua Instrument Co., Ltd, Shanghai, China) in a three-electrode system with a $1.0 \mathrm{M} \mathrm{KOH}$ electrolyte at room temperature. The working electrode was $\operatorname{Er}_{0.4}$ $\mathrm{Fe}-\mathrm{MOF} / \mathrm{NF}$, the counter electrode was a graphite plate, and $\mathrm{Hg} / \mathrm{HgO}$ was used as the reference electrode. All the potentials were reported as one form of the reversible hydrogen electrode $(\mathrm{RHE})$, calculated using the Nernst equation: $\mathrm{E}(\mathrm{RHE})=\mathrm{E}(\mathrm{Hg} / \mathrm{HgO})+0.059 \times \mathrm{pH}) \mathrm{V}$.

\subsection{Characterizations}

XRD data were acquired from a LabX XRD-6100 X-ray diffractometer with $\mathrm{Cu} \mathrm{K} \alpha$ radiation $(40 \mathrm{kV}, 30 \mathrm{~mA})$ and a $0.154 \mathrm{~nm}$ wavelength (Shimadzu, Osaka, Japan). SEM images were obtained using a XL30 ESEM FEG at a $20 \mathrm{kV}$ accelerating voltage. The TEM and EDX data were collected using a FEI Tecnai G2 F20 (FEI Company, Hillsboro, OR, USA) and OXFORD X-max 80T (FEI Company, Hillsboro, OR, USA). A Thermo Scientific K-Alpha X-ray photoelectron spectrometer (Thermo Fisher Scientific, Waltham, MA, USA) using Al was used to acquire XPS spectra. Raman measurements were conducted on a Renishaw Invia spectrometer (Renishaw Company, Gloucestershire, England). Fouriertransform infrared (FTIR) spectroscopy was carried out on an FTIR spectrometer (Theromo Nicolet Corporation, Madison, WI, USA) using the potassium bromide pellet method at an ambient temperature. 


\section{Results}

\subsection{The Structure and Composition of $E r_{0.4} \mathrm{Fe}-\mathrm{MOF} / \mathrm{NF}$}

The structure of $\mathrm{Er}_{0.4} \mathrm{Fe}-\mathrm{MOF}$ and Fe-MOF were characterized via X-ray diffraction (XRD), as shown in Figure $1 \mathrm{a}$ and Figure S1. The diffraction peaks at $8.9^{\circ}, 11.4^{\circ}, 15.6^{\circ}, 18.7^{\circ}$ and $20.8^{\circ}$ (marked as " ${ }^{\prime \prime}$ ) were indexed to the typical MIL-53 structure [25]. Meanwhile, we prepared a series of catalysts with different $\mathrm{Er} / \mathrm{Fe}$ molar ratios by adjusting the $\mathrm{Er}$ doping molar amount. As evidenced by Figure S1, the XRD patterns of these sample were similar, which excluded the formation of new crystal phases after Er doping. But the crystallinity of these catalysts increased with an increase in Er ions. Subsequently, the Fourier-transform infrared spectrum of $\mathrm{Er}_{0.4} \mathrm{Fe}-\mathrm{MOF}$ exhibited similar functional groups as those of Fe-MOF in the range of $4000-400 \mathrm{~cm}^{-1}$ (Figure 1b). The absorption bands at $750 \mathrm{~cm}^{-1}$ and $3432 \mathrm{~cm}^{-1}$ indicated the $\mathrm{C}-\mathrm{H}$ bending vibration of the benzene ring and the $\mathrm{O}-\mathrm{H}$ stretching vibration. The two peaks at 1662 and $1386 \mathrm{~cm}^{-1}$ contributed to the symmetric vibration of carboxyl groups. The peak at $541 \mathrm{~cm}^{-1}$ was observed to be metal-oxygen bond $(\mathrm{Fe}-\mathrm{O})$ vibrations, further demonstrating the coordination structure of MOFs [26].
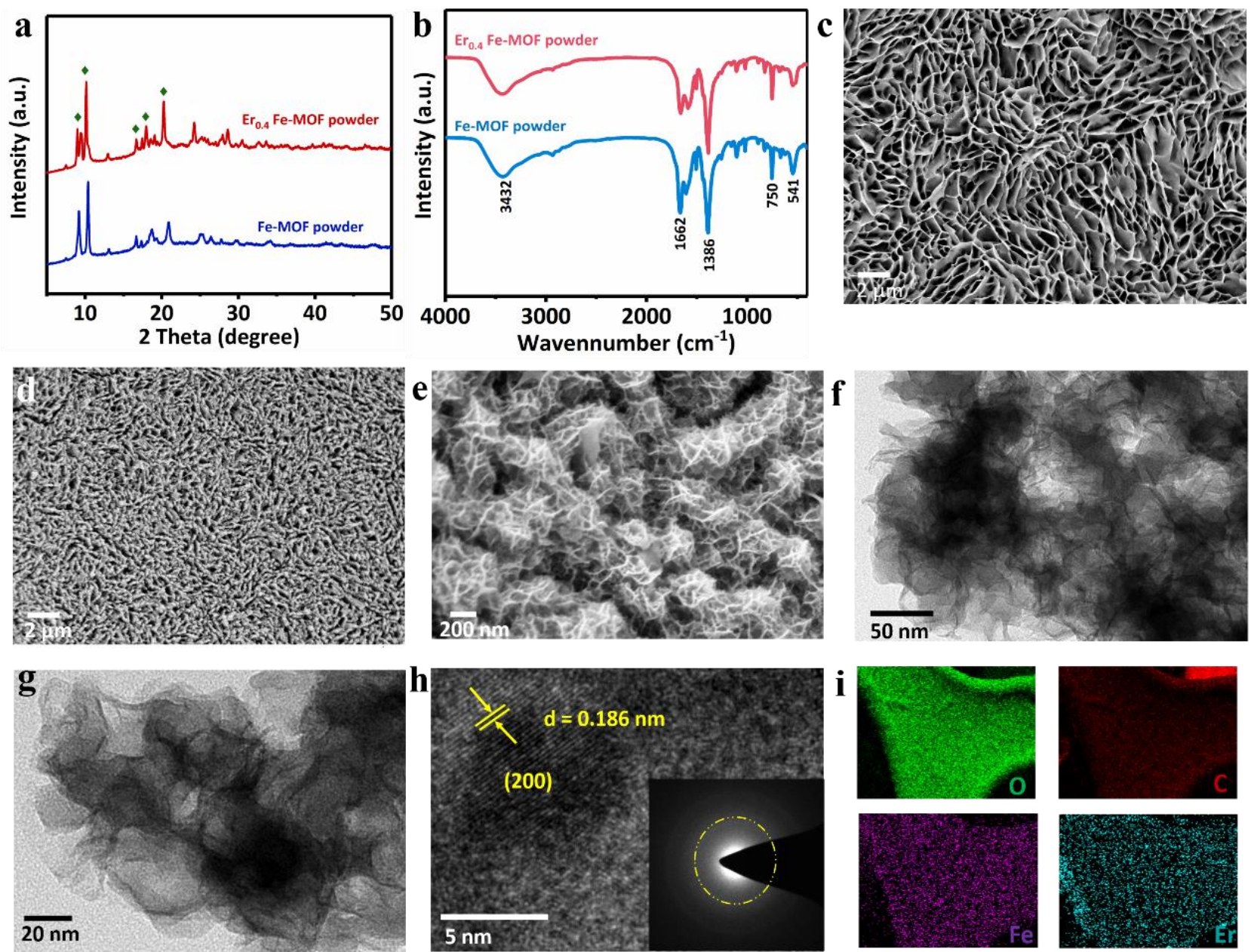

Figure 1. XRD patterns (a) and FTIR spectra (b) of Fe-MOF/NF and $\mathrm{Er}_{0.4} \mathrm{Fe}-\mathrm{MOF} / \mathrm{NF}$. SEM image of Fe-MOF/NF (c). SEM images (d,e), TEM images (f,g), HRTEM image (h) (inset was the corresponding SAED pattern), and element mapping (i) of $\mathrm{Er}_{0.4} \mathrm{Fe}-\mathrm{MOF} / \mathrm{NF}$.

Raman spectra, providing information about chemical bonding, displayed two peaks at 1613 and $1442 \mathrm{~cm}^{-1}$, attributed to the stretching modes of the carboxylate group (Figure S2) $[27,28]$. Moreover, the out-of-plane deformation modes of the $\mathrm{C}-\mathrm{H}$ groups 
appeared at $866,634 \mathrm{~cm}^{-1}$ [28]. In addition, the as-prepared $\mathrm{Er}_{0.4} \mathrm{Fe}-\mathrm{MOF}$ was uniformly grown on the surface of the 3D nickel foam in the form of a nanoarray structure, which was much thinner than the Fe-MOF (Figure 1c-e). The above structure could expose more specific surface area be beneficial to the mass transport for expediting the OER reaction. As shown in Figure 1f,g, ultrathin nanosheets loosely stacked could be easily observed using a transmission electron microscope (TEM). The high-resolution TEM image (HRTEM) in Figure $1 \mathrm{~h}$ shows that the lattice distance with an interplanar spacing of $0.186 \mathrm{~nm}$ denoted the (200) planes of MIL-53, corresponding to selected-area electron diffraction (SAED) pattern $[29,30]$. The energy-dispersive X-ray spectroscopy (EDX) and mappings (Figure 1i) certified the existence of Er after Er doping and distribution over the entire catalyst (Figures S3 and S4). These test results demonstrated that Er ions were doped into the Fe-MOF host without the formation of an additional phase.

The chemical compositions of $\mathrm{Er}_{0.4} \mathrm{Fe}-\mathrm{MOF} / \mathrm{NF}$ and Fe-MOF/NF were further characterized via X-ray photoelectron spectroscopy (XPS). The atomic percentages of $\mathrm{O}, \mathrm{Er}, \mathrm{C}$, and $\mathrm{Fe}$ in the $\mathrm{Er}_{0.4} \mathrm{Fe}-\mathrm{MOF}$ surface were 54.34, 0.19, 43.57, and 1.89, respectively, which approximately agreed with the EDX results. For C 1s (Figure 2a), three typical peaks located at $284.53,285.64$, and $288.43 \mathrm{eV}$, corresponding to the benzene ring, $\mathrm{C}-\mathrm{O}$ from the benzoate anions, and the carboxylate groups $(\mathrm{O}-\mathrm{C}=\mathrm{O})$ in terephthalic acid [31], respectively. The binding energy of $\mathrm{O} 1 \mathrm{~s}$ at $531.22,532.15$, and $533.12 \mathrm{eV}$ could be assigned to oxygen atoms of the $\mathrm{Fe}-\mathrm{O}$ bonds, the carboxylate groups of terephthalic acid, and absorbed water (Figure 2b) [31]. The $\mathrm{C} 1 \mathrm{~s}$ and $\mathrm{O} 1 \mathrm{~s}$ spectra of $\mathrm{Er}_{0.4} \mathrm{Fe}-\mathrm{MOF} / \mathrm{NF}$ and Fe-MOF/NF had the same shape and binding energy, implying their identical chemical composition. Figure $2 \mathrm{c}$ shows the XPS spectra of Fe $2 \mathrm{p}$ with the peak position at around $710.88 \mathrm{eV}$ and $724.13 \mathrm{eV}$, suggesting the valence state of $\mathrm{Fe}$ exists as $\mathrm{Fe}^{3+}$ in $\mathrm{Er}_{0.4} \mathrm{Fe}-\mathrm{MOF} / \mathrm{NF}$ and $\mathrm{Fe}-\mathrm{MOF} / \mathrm{NF}$ [32] In contrast, the binding energy of $\mathrm{Fe} 2 \mathrm{p}$ in $\mathrm{Er}_{0.4} \mathrm{Fe}-\mathrm{MOF} / \mathrm{NF}$ showed a negative shift at about $0.5-0.95 \mathrm{eV}$, indicating the change redistribution occurs after Er doping [33]. The reason for this may be the different electronegativities of $\mathrm{Fe}$ (1.83) and $\operatorname{Er}$ (1.24), causing additional electron density donation from Er to Fe [34]. Er doping could change the electronic environment of $\mathrm{Er}_{0.4} \mathrm{Fe}-\mathrm{MOF} / \mathrm{NF}$, resulting in different adsorption energies of intermediates, and thus accelerating the whole reaction process [35,36]. For the Er 4d spectrum (Figure 2d), the peak at $169.52 \mathrm{eV}$ confirms the Er element, further indicating the successful incorporation of Er into Fe-MOF/NF [37]. Compared with the single Er element $(167.3 \mathrm{eV})$, the Er element in $\mathrm{Er}_{0.4} \mathrm{Fe}-\mathrm{MOF} / \mathrm{NF}$ shifted to a positive binding energy, further demonstrating that the electrons may transfer from Er to Fe. Thus, deducing from all the above facts, the combination of Er and Fe could introduce surprising synergistic effects that may affect certain mechanisms through the modification of the electronic structures of host materials, leading to the promotion of the water splitting reaction.

\subsection{Electrochemical Properties of Er $r_{0.4}$ Fe-MOF/NF Electrode Active Materials}

The electrocatalytic performance of the electrodes toward OER were tested in $1.0 \mathrm{M}$ $\mathrm{KOH}$ solution through a typical three-electrode system at a scan rate of $2 \mathrm{mV} \mathrm{s}^{-1}$. All the overpotentials were given with iR-compensation unless specified [38]. Figure 3a showed the linear scan voltammetry (LSV) curves of bare NF, commercial $\mathrm{RuO}_{2} / \mathrm{NF}$, precursor $\mathrm{Fe}-\mathrm{MOF} / \mathrm{NF}$, and $\mathrm{Er}_{0.4} \mathrm{Fe}-\mathrm{MOF} / \mathrm{NF}$ electrodes for comparison. A pronounced oxidation peak existed at around $1.41 \mathrm{~V}$ vs. RHE, which was attributed to the oxidation of $\mathrm{Ni}^{2+}$ to $\mathrm{Ni}^{3+}$ of the substrate NF [39]. The current density then increased monotonically with the increase of applied potential after the above oxidation peak. At $100 \mathrm{~mA} \mathrm{~cm}^{-2}$, the $\mathrm{Er}_{0.4} \mathrm{Fe}$ MOF/NF exhibited the lowest overpotential ( $248 \mathrm{mV})$, compared with bare NF (418 mV), precursor Fe-MOF/NF $(336 \mathrm{mV})$ and commercial $\mathrm{RuO}_{2} / \mathrm{NF}(288 \mathrm{mV})$. It was notable that $\mathrm{Er}_{0.4} \mathrm{Fe}-\mathrm{MOF} / \mathrm{NF}$ exhibited excellent electrocatalytic activity, surpassing most of the previous OER catalysts [40-49], as shown in Figure $3 \mathrm{~b}$ and Table S3. $\mathrm{Er}_{0.4} \mathrm{Fe}-\mathrm{MOF} / \mathrm{NF}$ needed an overpotential of $210 \mathrm{mV}$ at low current density $\left(10 \mathrm{~mA} \mathrm{~cm}{ }^{-2}\right)$ by the back sweep test (Figure S5). To get additional insights into the influence of the Er content on the OER activity, a series of Er-doped Fe-MOF/NF were prepared with varying ratios of Er 
and Fe. For a more intuitive representation, histograms of samples with different doping concentrations were drawn according to the overpotential of LSV polarization curves, as shown in Figure S6. Interestingly, with the increasing Er doping amount, the Er-doped Fe-MOF/NF needed lower overpotentials at current densities of $100 \mathrm{~mA} \mathrm{~cm}^{-2}$. But the activity decreased as the Er content further grew to $0.4 \mathrm{mmol}$ or larger. The OER activity was positively linked to the Er doping content, highlighting the fact that the proper content of Er doping into MOFs could optimize OER activity. As displayed in Figure 3c, the Tafel slope of $\mathrm{Er}_{0.4} \mathrm{Fe}-\mathrm{MOF} / \mathrm{NF}$ was determined to be $73 \mathrm{mV} \mathrm{dec}^{-1}$, which was much lower than those of Fe-MOF/NF (132 $\left.\mathrm{mV} \mathrm{dec}^{-1}\right)$, commercial $\mathrm{RuO}_{2} / \mathrm{NF}\left(131 \mathrm{mV} \mathrm{dec}^{-1}\right)$ and bare NF $\left(256 \mathrm{mV} \mathrm{dec}^{-1}\right)$, indicating the fast OER kinetics of $\mathrm{Er}_{0.4} \mathrm{Fe}-\mathrm{MOF} / \mathrm{NF}$. Excitingly, the low overpotential and Tafel slope of $\mathrm{Er}_{0.4} \mathrm{Fe}-\mathrm{MOF} / \mathrm{NF}$ corroborated that the synergistic effects of Er and Fe ions provided a crucial factor the excellent alkaline OER catalytic activity. Furthermore, the electrochemical impedance spectroscopies (EISs) shown in Figure 3d revealed that $\mathrm{Er}_{0.4} \mathrm{Fe}-\mathrm{MOF} / \mathrm{NF}$ had a smaller semicircle radius than those of Fe-MOF/NF, $\mathrm{RuO}_{2} / \mathrm{NF}$, and NF, implying prominently improved interfacial electron-transfer kinetics over $\mathrm{Er}_{0.4} \mathrm{Fe}-\mathrm{MOF} / \mathrm{NF}$. The improved conductivity of $\mathrm{Er}_{0.4} \mathrm{Fe}-\mathrm{MOF} / \mathrm{NF}$ revealed that the electronic structure of the sample had changed after Er doping, which agreed with the XPS results. Meanwhile, the EISs of Er-doped Fe-MOF/NF with different Er/Fe atomic ratios are displayed in Figure S7. Importantly, $\mathrm{Er}_{0.4} \mathrm{Fe}-\mathrm{MOF} / \mathrm{NF}$ exhibited excellent OER catalytic performance at high current densities (including $500 \mathrm{~mA} \mathrm{~cm}^{-2}$ and $1000 \mathrm{~mA} \mathrm{~cm}^{-2}$ ). As shown in Figure 3e, $\mathrm{Er}_{0.4} \mathrm{Fe}-\mathrm{MOF} / \mathrm{NF}$ achieved overpotentials of 297 and $326 \mathrm{mV}$ to drive 500 and $1000 \mathrm{~mA} \mathrm{~cm}^{-2}$ current densities, respectively, lower than that of Fe-MOF/NF $\left(\eta_{500}=448 \mathrm{mV} ; \eta_{1000}=539 \mathrm{mV}\right)$, to meet the strict criteria of industrial applications. As revealed in Figure $3 \mathrm{f}$ and Table $\mathrm{S} 4, \mathrm{Er}_{0.4} \mathrm{Fe}-\mathrm{MOF} / \mathrm{NF}$ was comparable to the other reported state-of-the-art catalysts (Figure $3 \mathrm{f}$ and Table S4) [43,49-52].
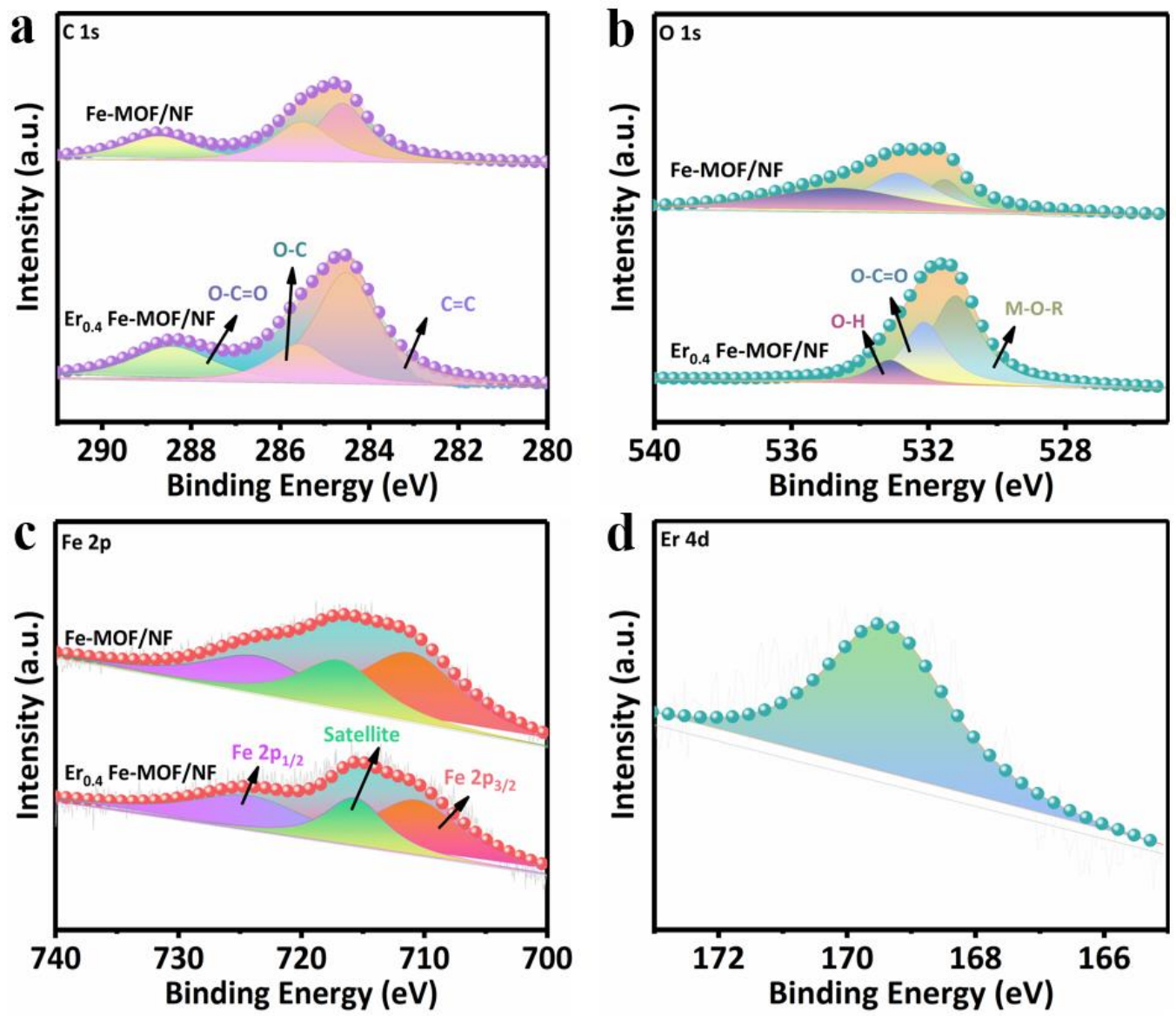

Figure 2. The XPS spectra of $\mathrm{C}$ 1s (a), O 1s (b), Fe 2p (c) and Er 4d (d) of $\mathrm{Er}_{0.4} \mathrm{Fe}-\mathrm{MOF} / \mathrm{NF}$ and Fe-MOF/NF. 

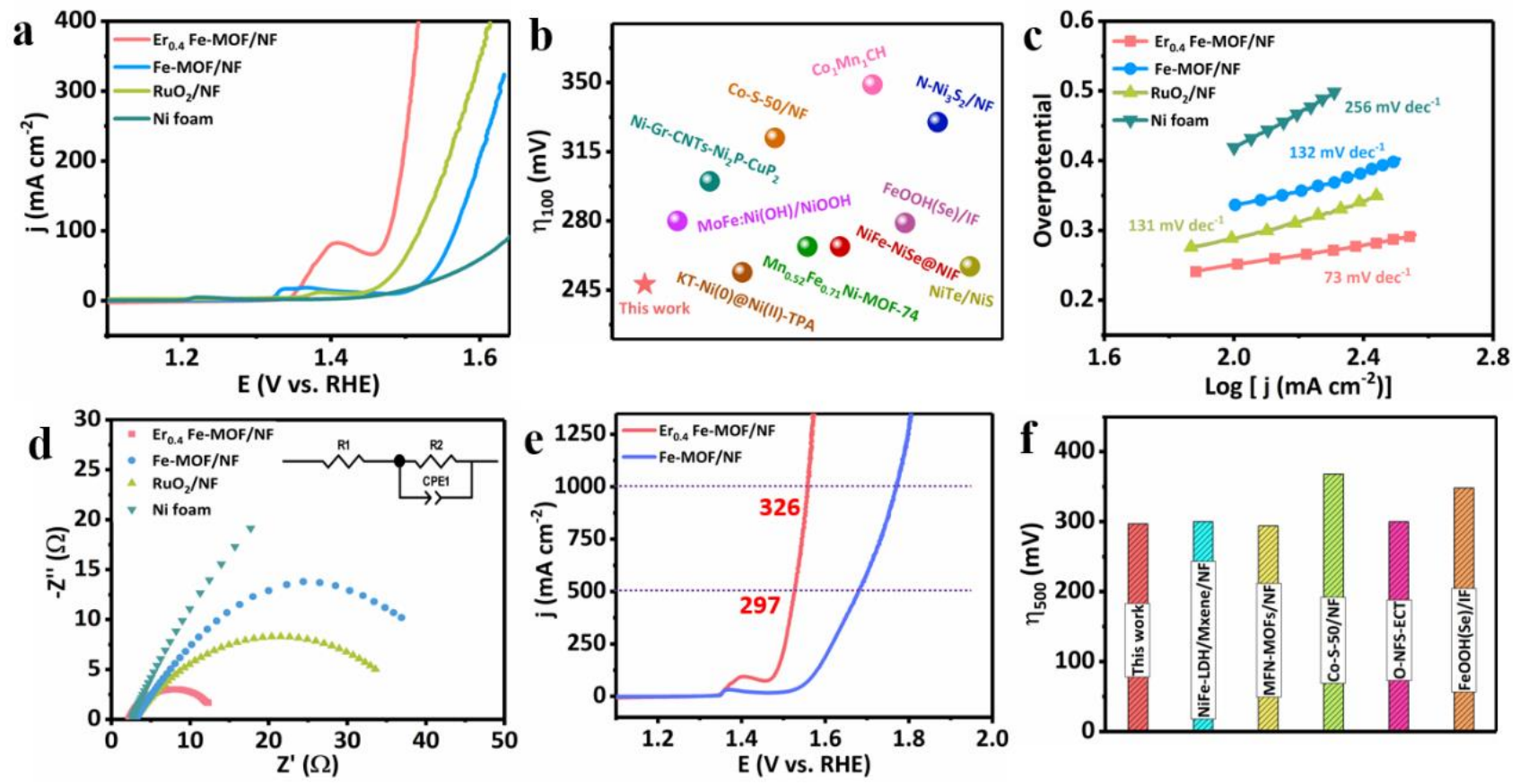

Figure 3. LSV curves of NF-based electrodes tested in $1.0 \mathrm{M} \mathrm{KOH} \mathrm{(a).} \mathrm{Comparing} \mathrm{the} \mathrm{overpotential} \mathrm{of} \mathrm{Er}_{0.4} \mathrm{Fe}-\mathrm{MOF} / \mathrm{NF}$ at $100 \mathrm{~mA} \mathrm{~cm}^{-2}$ with other literatures (b). Tafel slopes (c) and EIS (d) of Ni foam, Fe-MOF/NF, commercial $\mathrm{RuO}_{2}$ and Er 0.4 Fe-MOF/NF. LSV curves (e) and OER performance comparison histogram (f).

Figure 4a displayed a continuous multistep chronopotentiometry curve for $\mathrm{Er}_{0.4} \mathrm{Fe}-$ $\mathrm{MOF} / \mathrm{NF}$. The initial current density was $30 \mathrm{~mA} \mathrm{~cm}^{-2}$ and the corresponding potential stabilized at the initial current density, remaining unchanged for 3600 seconds. Similar results have been observed for current values $\left(30-250 \mathrm{~mA} \mathrm{~cm}^{-2}\right)$, indicating excellent mass transfer, electric conductivity, and mechanical robustness of $\mathrm{Er}_{0.4} \mathrm{Fe}-\mathrm{MOF} / \mathrm{NF}$ [53]. The OER stability of MOFs at large current densities is very important for industrial applications. Obviously, the OER performance of $\mathrm{Er}_{0.4} \mathrm{Fe}-\mathrm{MOF} / \mathrm{NF}$ could be well maintained for at least $100 \mathrm{~h}$ at the large current density of $100 \mathrm{~mA} \mathrm{~cm}^{-2}$ without obvious degradation. The SEM image (the insert in Figure 4b) and XPS spectra (Figure S8) of $\mathrm{Er}_{0.4} \mathrm{Fe}-\mathrm{MOF} / \mathrm{NF}$ display its original morphology and composition after long-term OER testing, suggesting excellent durability of the $\mathrm{Er}_{0.4} \mathrm{Fe}-\mathrm{MOF} / \mathrm{NF}$ catalyst. However, the peaks of $\mathrm{O} 1$ s originated from $\mathrm{O}-\mathrm{H}(533.12 \mathrm{eV})$, the carboxyl group $(532.15 \mathrm{eV})$, and $\mathrm{M}-\mathrm{O}(531.22 \mathrm{eV})$ shifted to the lower binding energy of $532 / 530.7 \mathrm{eV}$, demonstrating the possible formation of oxyhydroxide during OERs [26]. Furthermore, for commercial applications, the stability of electrocatalysis under large current densities was essential for large-scale production because the intrinsic instability of MOFs and the number of gas bubbles generated. As a result, it was evident that just $9 \%$ decay in current densities could be observed for the $500 \mathrm{~mA} \mathrm{~cm}^{-2}$ case after $25 \mathrm{~h}$, while the Fe-MOF/NF catalyst dropped quickly under the same test conditions, as shown in Figure 4c. Subsequently, as shown in Figure S9, the obtained LSV curves after the 1st and the 1000th cyclic CV sweeps exhibited seldom decay. These test results further confirmed the positive effect of Er doping in enhancing both the OER activity and stability of Fe-MOF/NF. 
a

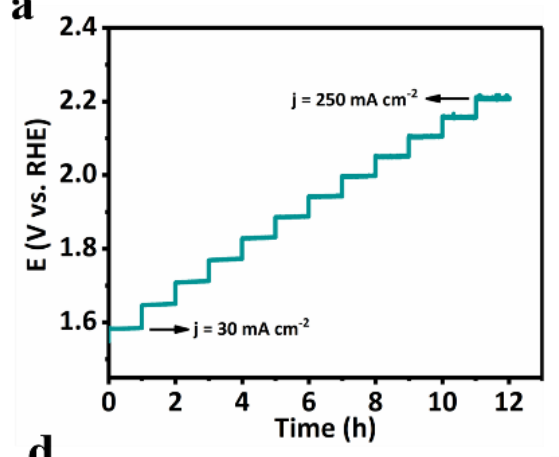

d

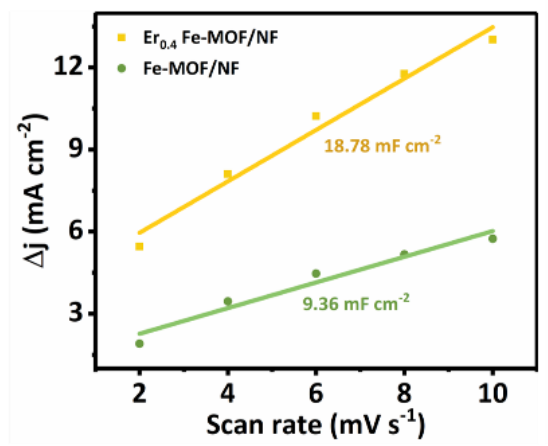

b
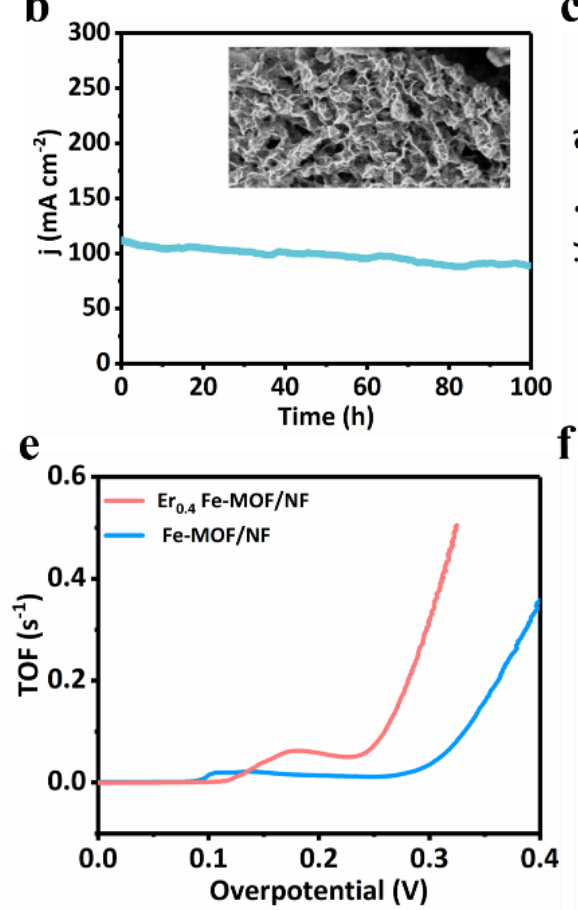

c

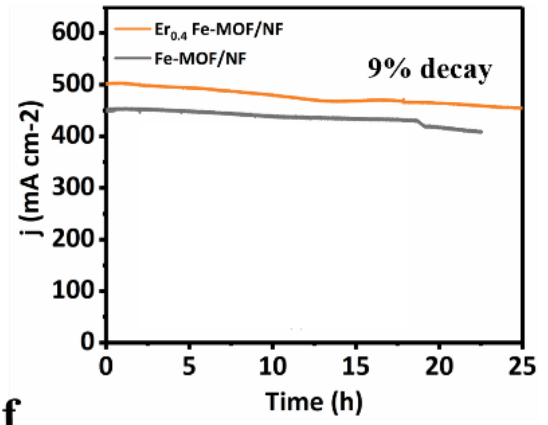

f

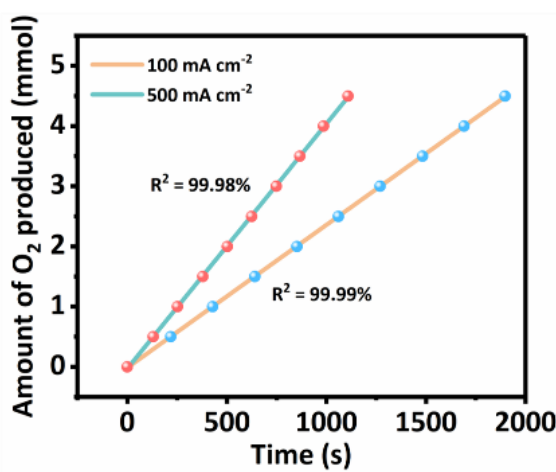

Figure 4. The multi-current process curve of $\mathrm{Er}_{0.4} \mathrm{Fe}-\mathrm{MOF} / \mathrm{NF}$ (a) obtained at current densities of 30-250 mA cm $\mathrm{m}^{-2}$, every $3600 \mathrm{~s}$, respectively. Chronoamperometric (i-t) curves at current densities of $100 \mathrm{~mA} \mathrm{~cm}^{-2}$ (b), inset was the SEM image after testing. Chronoamperometric curves of $\mathrm{Er}_{0.4} \mathrm{Fe}-\mathrm{MOF} / \mathrm{NF}$ and Fe-MOF/NF (c). ECSA evolutions (d) and TOF values (e) of $\mathrm{Er}_{0.4} \mathrm{Fe}-\mathrm{MOF} / \mathrm{NF}$ and $\mathrm{Fe}-\mathrm{MOF} / \mathrm{NF}$. Experimental amounts of $\mathrm{O}_{2}$ generated by the $\mathrm{Er}_{0.4} \mathrm{Fe}-\mathrm{MOF} / \mathrm{NF}$ electrode at 100 and $500 \mathrm{~mA} \mathrm{~cm}^{-2}$ (f).

The mechanism of OER could be assigned to the existence of the two pairs of redox peaks in Figure S10. In the forward half cycle, the oxidation peak can be attributed to the oxidation of $\mathrm{Fe}^{3+}$ to $\mathrm{Fe}^{4+}$ at about $1.54 \mathrm{~V}$ vs. RHE. Moreover, in the reverse half-cycle, the peak located at $1.15 \mathrm{~V}$ vs. RHE can be attributed to the reduction of $\mathrm{Fe}^{4+}$ to $\mathrm{Fe}^{3+}$ [54]. In contrast, the oxidation peak and reduction peak of bare NF were almost negligible in the same voltage range, indicating the promotion of OERs came from $\mathrm{Er}_{0.4} \mathrm{Fe}-\mathrm{MOF}$ instead of the substrate NF. Obviously, the intensity redox peaks of $\mathrm{Er}_{0.4} \mathrm{Fe}-\mathrm{MOF} / \mathrm{NF}$ were higher than those of the precursor Fe-MOF/NF due to the synergistic effect between Er and Fe sites. Based on the above test results, the OER performance of $\mathrm{Er}_{0.4} \mathrm{Fe}-\mathrm{MOF} / \mathrm{NF}$ could be assigned to the following steps: [54]

$$
\begin{gathered}
\mathrm{A}+\mathrm{OH}^{-} \leftrightarrow \mathrm{AOH}+\mathrm{e}^{-} \\
\mathrm{AOH}+\mathrm{OH}^{-} \leftrightarrow \mathrm{AO}+\mathrm{H}_{2} \mathrm{O}+\mathrm{e}^{-} \\
\mathrm{AO}+\mathrm{OH}^{-} \leftrightarrow \mathrm{AOOH}+\mathrm{e}^{-} \\
\mathrm{AOOH}+\mathrm{OH}^{-} \leftrightarrow \mathrm{A}+\mathrm{O}_{2}+\mathrm{H}_{2} \mathrm{O}+\mathrm{e}^{-}
\end{gathered}
$$

where A denotes active sites of $\mathrm{Er}_{0.4} \mathrm{Fe}-\mathrm{MOF} / \mathrm{NF}$. Thus, Fe sites served as the active sites in this electrode.

The double-layer capacitances $\left(\mathrm{C}_{\mathrm{dl}}\right)$ obtained from CV curves (Figure $\left.\mathrm{S11}\right)$ were calculated to evaluate the electrochemically active surface area [55]. In Figure $4 d$, the $C_{d l}$ value of $\mathrm{Er}_{0.4} \mathrm{Fe}-\mathrm{MOF} / \mathrm{NF}$ was calculated to be $18.78 \mathrm{mF} \mathrm{cm}^{-2}$, significantly higher than that of the precursor Fe-MOF/NF $\left(9.36 \mathrm{mF} \mathrm{cm}^{-2}\right)$. The reason was attributed to the high exposure of active sites provided by the ultrathin nanoarray structure. Similarly, the intrinsic catalytic performance of this electrode was also evaluated by the turnover frequency 
(TOF). The calculated TOF values were tested through CV curves (Figure S12) based on a previous report. [56] As shown in Figure 4e, $\mathrm{Er}_{0.4} \mathrm{Fe}-\mathrm{MOF} / \mathrm{NF}$ achieved a TOF value of $0.3 \mathrm{O}_{2} \mathrm{~s}^{-1}$ while that of Fe-MOF/NF was only $0.04 \mathrm{O}_{2} \mathrm{~s}^{-1}$ at the same overpotential of $300 \mathrm{mV}$. The faradic efficiency (FE) for OER was calculated by comparing the amount of estimated oxygen gas volume using both the experimental and theoretical methods under $100 \mathrm{~mA} \mathrm{~cm}^{-2}$ and $500 \mathrm{~mA} \mathrm{~cm}^{-2}$ current densities of $\mathrm{Er}_{0.4} \mathrm{Fe}_{\mathrm{MOF}} \mathrm{NF}$ (assuming $100 \%$ FE), as shown in Figure 4f. Virtually 100\% FE was obtained, indicating most of the surface electrons participated the OER process and the charge transfer process exhibited a minimum blocking resistance [57].

\section{Conclusions}

In summary, with optimized Er doping, ultrahigh activity and stability for OER electrocatalysts has been achieved using a one-step solvothermal method. Compared with the precursor Fe-MOF/NF, the $\mathrm{Er}_{0.4}$ Fe-MOF/NF electrode showed OER performance can yield a $100 \mathrm{~mA} \mathrm{~cm}^{-2}$ current density at an overpotential of $248 \mathrm{mV}$ with long-term electrochemical durability for at least $100 \mathrm{~h}$. Moreover, it also exhibited ultralow overpotentials of 297 and $326 \mathrm{mV}$ to reach the large current densities of 500 and $1000 \mathrm{~mA} \mathrm{~cm}^{-2}$. Overall, the addition of Er dopants could have a significant impact on OER catalytic performance due to the optimized electronic structure of the active center.

Supplementary Materials: The following are available online at https: / www.mdpi.com/article / 10.3390/nano11071847/s1, Figure S1: The XRD patterns of different Er content of Er-doped Fe$\mathrm{MOF} / \mathrm{NF}$, Figure S2: Raman spectra of $\mathrm{Er}_{0.4} \mathrm{Fe}-\mathrm{MOF} / \mathrm{NF}$ and Fe-MOF/NF, Figure S3: The EDX spectrum of $\mathrm{Er}_{0.4} \mathrm{Fe}-\mathrm{MOF} / \mathrm{NF}$, Table S1: The element percentages $\mathrm{Wt} \%$ of $\mathrm{Er}_{0.4} \mathrm{Fe}-\mathrm{MOF} / \mathrm{NF}$, Figure S4: The EDX spectrum of Fe-MOF/NF, Table S2: The element percentages $\mathrm{W} t \%$ of Fe-MOF/NF, Figure S5: LSV of $\mathrm{Er}_{0.4} \mathrm{Fe}-\mathrm{MOF} / \mathrm{NF}$ for OER in $1.0 \mathrm{M} \mathrm{KOH}$, Figure S6: LSV curves (a) and comparing the overpotential of different Er content of Er-doped Fe-MOF/NF at $100 \mathrm{~mA} \mathrm{~cm}^{-2}$ (b,c), Figure S7: EIS of different Er content of Er-doped Fe-MOF/NF, Figure S8: The XPS spectra of C 1s (a), O 1s (b), Fe 2p (c) and Er (d) after i-t testing, Figure S9: LSV curves of $\mathrm{Er}_{0.4} \mathrm{Fe}-\mathrm{MOF} / \mathrm{NF}$ before and after $1000 \mathrm{CV}$ cycles in $1.0 \mathrm{M} \mathrm{KOH}$, Figure S10: CV curves of $\mathrm{Er}_{0.4}$ Fe-MOF/NF (a) and Fe-MOF/NF (b) (inset image was the $\mathrm{CV}$ of bare $\mathrm{NF}$ ) at a scan rate of $5 \mathrm{mV} \mathrm{s}^{-1}$, Figure S11: ECSA evaluations of $\mathrm{Er}_{0.4} \mathrm{Fe}-\mathrm{MOF} / \mathrm{NF}(\mathrm{a}, \mathrm{b})$ and Fe-MOF/NF $(\mathrm{c}, \mathrm{d})$, Figure S12: TOF evaluations of $\mathrm{Er}_{0.4} \mathrm{Fe}-\mathrm{MOF} / \mathrm{NF}(\mathrm{a}, \mathrm{b})$ and Fe-MOF/NF (c,d) with various scan rates $\left(20,40,60,80,100 \mathrm{mV} \mathrm{s}^{-1}\right)$, Table S3: Comparison of catalytic performance of $\mathrm{Er}_{0.4} \mathrm{Fe}-\mathrm{MOF} / \mathrm{NF}$ with other reported OER catalysts, Table S4: Comparison of catalytic performance of $\mathrm{Er}_{0.4} \mathrm{Fe}-\mathrm{MOF} / \mathrm{NF}$ with other reported OER catalysts at large current densities (above $250 \mathrm{~mA} \mathrm{~cm}^{-2}$ ).

Author Contributions: Conceptualization and writing original draft, Y.M. (Yan Ma); methodology: Y.M. (Yujie Miao) and G.M.; investigation: D.L.; supervision: C.X.; writing-review and editing: W.Z. and F.X.; project administration: F.X. All authors have read and agreed to the published version of the manuscript.

Funding: This research was funded by The State Key Laboratory of Electroanalytical Chemistry (SKLEAC201910).

Data Availability Statement: The data presented in this study are available on request from the corresponding author.

Conflicts of Interest: The authors declare no conflict of interest.

\section{References}

1. Jamesh, M.; Harb, M. Tuning the electronic structure of the earth-abundant electrocatalysts for oxygen evolution reaction (OER) to achieve efficient alkaline water splitting-A review. J. Energy Chem. 2021, 56, 299-342. [CrossRef]

2. Song, J.; Wei, C.; Huang, Z.F.; Liu, C.; Zeng, L.; Wang, X.; Xu, Z.J. A review on fundamentals for designing oxygen evolution electrocatalysts. Chem. Soc. Rev. 2020, 49, 2196-2214. [CrossRef]

3. Wu, J.; Li, P.; Parra, P.A.; Wu, S.; Lin, X.; Kramer, D.; Chen, S.; Kucernak, A. Controllable heteroatom doping effects of $\mathrm{Cr}_{\mathrm{x}} \mathrm{Co}_{2-\mathrm{x}} \mathrm{P}$ nanoparticles: A robust electrocatalyst for overall water splitting in alkaline solutions. ACS Appl. Mater. Inter. 2020, 12, 47397-47407. [CrossRef] [PubMed] 
4. Boppella, R.; Tan, J.; Yun, J.; Manorama, S.V.; Moon, J. Anion-mediated transition metal electrocatalysts for efficient water electrolysis: Recent advances and future perspectives. Coordin. Chem. Rev. 2021, 427, 213552. [CrossRef]

5. Chen, J.; Li, H.; Fan, C.; Meng, Q.; Tang, Y.; Qiu, X.; Fu, G.; Ma, T. Dual single-atomic Ni-N 4 and Fe-N 4 sites constructing janus hollow graphene for selective oxygen electrocatalysis. Adv. Mater. 2020, 32, 2003134. [CrossRef]

6. Hunter, B.M.; Gray, H.B.; Muller, A.M. Earth-abundant heterogeneous water oxidation catalysts. Chem. Rev. 2016, 116, 14120-14136. [CrossRef]

7. Anantharaj, S.; Ede, S.R.; Sakthikumar, K.; Karthick, K.; Mishra, S.; Kundu, S. Recent trends and perspectives in electrochemical water splitting with an emphasis on sulfide, selenide, and phosphide catalysts of Fe, Co and Ni: A review. ACS Catal. 2016, 6, 8069-8097. [CrossRef]

8. Fu, G.; Lee, J.M. Ternary metal sulfides for electrocatalytic energy conversion. J Mater. Chem. A 2019, 7, 9386-9405. [CrossRef]

9. Zhou, J.; Wang, Y.; Su, X.; Gu, S.; Liu, R.; Huang, Y.; Yan, S.; Li, J.; Zhang, S. Electrochemically accessing ultrathin Co(oxy)hydroxide nanosheets and operando identifying their active phase for the oxygen evolution reaction. Energ. Environ. Sci. 2019, 12, 739-746. [CrossRef]

10. Puerto, P.A.; Ng, K.L.; Fahy, K.; Goode, A.E.; Ryan, M.P.; Kucernak, A. Supported transition metal phosphides: Activity survey for HER, ORR, OER and corrosion resistance in acid and alkaline electrolytes. ACS Catal. 2019, 9, 11515-11529. [CrossRef]

11. Han, N.; Liu, P.; Jiang, J.; Ai, L.; Shao, Z.; Liu, S. Recent advances in nanostructured metal nitrides for water splitting. J. Mater. Chem. A 2018, 6, 19912-19933. [CrossRef]

12. Li, W.; Mukerjee, S.; Ren, B.; Cao, R.; Fischer, R.A. Open framework material based thin films: Electrochemical catalysis and state-of-the-art technologies. Adv. Energy Mater. 2021, in press.

13. Zheng, F.; Zhang, W.; Zhang, X.; Zhang, Y.; Chen, W. Sub-2 nm ultrathin and robust 2D FeNi layered double hydroxide nanosheets packed with 1D FeNi-MOFs for enhanced oxygen evolution electrocatalysis. Adv. Funct. Mater. 2021, in press. [CrossRef]

14. Li, Q.; Liu, Y.; Niu, S.; Li, C.; Chen, C.; Liu, Q.; Huo, J. Microwave-assisted rapid synthesis and activation of ultrathin trimetalorganic framework nanosheets for efficient electrocatalytic oxygen evolution. J. Colloid. Interf. Sci. 2021, 603, 148-156. [CrossRef]

15. Senthil, R.D.; Chuah, X.F.; Lu, S.Y. In Situ grown bimetallic MOF-based composite as highly efficient bifunctional electrocatalyst for overall water splitting with ultrastability at high current densities. Adv. Energy Mater. 2018, 8, 1801065. [CrossRef]

16. Liu, X.; Fan, X.; Huang, H.; Lin, H.P.; Gao, J. Electronic modulation of oxygen evolution on metal doped NiFe layered double hydroxides. J. Colloid. Interf. Sci. 2021, 587, 385-392. [CrossRef] [PubMed]

17. Su, H.; Song, S.; Li, S.; Gao, Y.; Ge, L.; Song, W.; Ma, T.; Liu, J. High-valent bimetal $\mathrm{Ni}_{3} \mathrm{~S}_{2} / \mathrm{Co}_{3} \mathrm{~S}_{4}$ induced by Cu doping for bifunctional electrocatalytic water splitting. Appl. Catal. B Environ. 2021, 293, 120225. [CrossRef]

18. Keevend, K.; Krummenacher, R.; Kungas, E.; Gerken, L.R.H.; Gogos, A.; Stiefel, M.; Herrmann, I.K. Correlative cathodoluminescence electron microscopy: Immunolabeling using rare-earth element doped nanoparticles. Small 2020, 16, 2004615. [CrossRef] [PubMed]

19. Wang, X.R.; Huang, Z.; Du, J.; Wang, X.Z.; Gu, N.; Tian, X.; Li, Y.; Liu, Y.Y.; Huo, J.Z.; Ding, B. Hydrothermal preparation of five rare-earth (re = Dy, Gd, Ho, Pr and Sm) luminescent cluster-based coordination materials: The first MOFs-based ratiometric fluorescent sensor for lysine and bifunctional sensing platform for insulin and $\mathrm{Al}^{3+}$. Inorg. Chem. 2018, 57, 12885-12899. [CrossRef]

20. Wan, Z.; Hu, M.; Hu, B.; Yan, T.; Wang, K.; Wang, X. Vacancy induced photocatalytic activity of $\mathrm{La} \operatorname{doped} \mathrm{In}(\mathrm{OH})_{3}$ for $\mathrm{CO}_{2}$ reduction with water vapor. Catal. Sci. Technol. 2020, 10, 2893-2904. [CrossRef]

21. Xu, H.; Shan, C.; Wu, X.; Sun, M.; Huang, B.; Tang, Y.; Yan, C.H. Fabrication of layered double hydroxide microcapsules mediated by cerium doping in metal-organic frameworks for boosting water splitting. Energ. Environ. Sci. 2020, 13, 2949-2956. [CrossRef]

22. Ahmad, I.; Shoaib, A.M.; Ahmed, E.; Ahmad, M.; Keller, V.; Qamar, K.W.; Khalid, N.R. Rare earth co-doped ZnO photocatalysts: Solution combustion synthesis and environmental applications. Sep. Purif. Techno. 2020, 237, 116328. [CrossRef]

23. Melillo, A.; Antonino, M.C.; Navalon, S.; Alvaro, M.; Ferrer, B. Enhancing visible-light photocatalytic activity for overall water splitting in UiO-66 by controlling metal node composition. Appl. Catal. B Environ. 2020, 278, 119345. [CrossRef]

24. Wang, X.; Xiao, Y.; Yu, H.; Yang, Y.; Dong, X.; Xia, L. Noble-metal-free MOF Derived ZnS/CeO 2 Decorated with CuS Cocatalyst Photocatalyst with Efficient Photocatalytic Hydrogen Production Character. ChemCatChem 2020, 12, 5669-5678. [CrossRef]

25. Chen, H.; Liu, Y.; Cai, T.; Dong, W.; Tang, L.; Xia, X.; Wang, L.; Li, T. Boosting photocatalytic performance in mixed-valence MIL-53(Fe) by changing Fe(II)/Fe(III) ratio. ACS Appl. Mater. Inter. 2019, 11, 28791-28800. [CrossRef] [PubMed]

26. Qian, Q.; Li, Y.; Liu, Y.; Yu, L.; Zhang, G. Ambient fast synthesis and active sites deciphering of hierarchical foam-like trimetalorganic framework nanostructures as a platform for highly efficient oxygen evolution electrocatalysis. Adv. Mater. 2019, 31, 1901139. [CrossRef] [PubMed]

27. Louie, M.W.; Bell, A.T. An investigation of thin-film Ni-Fe oxide catalysts for the electrochemical evolution of oxygen. J. Am. Chem. Soc. 2013, 135, 12329-12337. [CrossRef]

28. Bordiga, S.; Lamberti, C.; Ricchiardi, G.; Regli, L.; Bonino, F.; Damin, A.; Lillerud, K.-P.; Bjorgenb, M.; Zecchina, A. Electronic and vibrational properties of a MOF-5 metal-organic framework: ZnO quantum dot behaviour. Chem. Commun. 2004, 20, $2300-2301$. [CrossRef] [PubMed]

29. Sun, F.; Wang, G.; Ding, Y.; Wang, C.; Yuan, B.; Lin, Y. NiFe-based metal-organic framework nanosheets directly supported on nickel foam acting as robust electrodes for electrochemical oxygen evolution reaction. Adv. Energy Mater. 2018, 8, 1800584. [CrossRef]

30. Cao, C.; Ma, D.D.; Xu, Q.; Wu, X.T.; Zhu, Q.L. Semisacrificial template growth of self-supporting MOF nanocomposite electrode for efficient electrocatalytic water oxidation. Adv. Funct. Mater. 2018, 29, 1807418. [CrossRef] 
31. Chandra, V.; Park, J.; Chun, Y.; Woo, J.; Hwang, I.C.; Kim, K.S. Water-dispersible magnetite-reduced graphene oxide composities for arsenic removal. ACS Nano 2010, 4, 3976-3986. [CrossRef] [PubMed]

32. Araya, T.; Jia, M.; Yang, J.; Zhao, P.; Cai, K.; Ma, W.; Huang, Y. Resin modified MIL-53 (Fe) MOF for improvement of photocatalytic performance. Appl. Catal. B Environ. 2017, 203, 768-777. [CrossRef]

33. Chen, J.Y.; Dang, L.; Liang, H.; Bi, W.; Gerken, J.B.; Jin, S.; Stahl, S.S. Operando analysis of NiFe and Fe oxyhydroxide electrocatalysts for water oxidation: Detection of $\mathrm{Fe}^{4+}$ by mossbauer spectroscopy. J. Am. Chem. Soc. 2015, 137, 15090-15093. [CrossRef] [PubMed]

34. Li, F.; Bu, Y.; Lv, Z.; Mahmood, J.; Han, G.F.; Ahmad, I.; Kim, G.; Zhong, Q.; Baek, J.-B. Porous cobalt phosphide polyhedrons with iron doping as an efficient bifunctional electrocatalyst. Small 2017, 13, 1701167. [CrossRef] [PubMed]

35. Tsai, F.T.; Deng, Y.T.; Pao, C.W.; Chen, J.L.; Lee, J.F.; Lai, K.T.; Liaw, W.F. The HER/OER mechanistic study of an FeCoNi-based electrocatalyst for alkaline water splitting. J. Mater. Chem. A 2020, 8, 9939-9950. [CrossRef]

36. Anantharaj, S.; Kundu, S.; Noda, S. "The Fe effect": A review unveiling the critical roles of Fe in enhancing OER activity of Ni and Co based catalysts. Nano Energy 2021, 80, 105514. [CrossRef]

37. Zhang, G.; Wang, B.; Bi, J.; Fang, D.; Yang, S. Constructing ultrathin CoP nanomeshes by Er-doping for highly efficient bifunctional electrocatalysts for overall water splitting. J. Mater. Chem. A 2019, 7, 5769-5778. [CrossRef]

38. Xie, M.; Ma, Y.; Lin, D.; Xu, C.; Xie, F.; Zeng, W. Bimetal-organic framework MIL-53(Co-Fe): An efficient and robust electrocatalyst for the oxygen evolution reaction. Nanoscale 2020, 12, 67-71. [CrossRef]

39. Zhang, X.; Li, J.; Yang, Y.; Zhang, S.; Zhu, H.; Zhu, X.; Xing, H.; Zhang, Y.; Huang, B.; Guo, S.; et al. $\mathrm{Co}_{3} \mathrm{O}_{4} / \mathrm{Fe}_{0.33} \mathrm{Co}_{0.66} \mathrm{P}$ interface nanowire for enhancing water oxidation catalysis at high current density. Adv Mater. 2018, 30, 1803551. [CrossRef]

40. Jin, Y.; Huang, S.; Yue, X.; Du, H.; Shen, P.K. Mo- and Fe-modified $\mathrm{Ni}(\mathrm{OH})_{2} / \mathrm{NiOOH}$ nanosheets as highly active and stable electrocatalysts for oxygen evolution reaction. ACS Catal. 2018, 8, 2359-2363. [CrossRef]

41. Riyajuddin, S.; Azmi, K.; Pahuja, M.; Kumar, S.; Maruyama, T.; Bera, C. Super-hydrophilic hierarchical Ni-foam-graphene-carbon nanotubes- $\mathrm{Ni}_{2} \mathrm{P}-\mathrm{CuP}{ }_{2}$ nano-architecture as efficient electrocatalyst for overall water splitting. ACS Nano 2021, 15, 5586-5599. [CrossRef] [PubMed]

42. Hu, Q.; Wang, Z.; Huang, X.; Qin, Y.; Yang, H.; Ren, X. Integrating well-controlled core-shell structures into "superaerophobic" electrodes for water oxidation at large current densities. Appl. Catal. B Environ. 2021, 286, 119920. [CrossRef]

43. Yang, W.; Zeng, J.; Hua, Y.; Xu, C.; Siwal, S.S.; Zhang, Q. Defect engineering of cobalt microspheres by S doping and electrochemical oxidation as efficient bifunctional and durable electrocatalysts for water splitting at high current densities. J. Power Sources 2019, 436, 226887. [CrossRef]

44. Zhou, W.; Xue, Z.; Liu, Q.; Li, Y.; Hu, J.; Li, G. Trimetallic MOF-74 films grown on Ni foam as bifunctional electrocatalysts for overall water splitting. ChemSusChem 2020, 13, 5647-5653. [CrossRef]

45. Chen, J.; Chen, J.; Cui, H.; Wang, C. Electronic structure and crystalline phase dual modulation via anion-cation Co-doping for boosting oxygen evolution with long-term stability under large current density. ACS Appl. Mater. Inter. 2019, 11, 34819-34826. [CrossRef]

46. Tang, T.; Jiang, W.J.; Niu, S.; Liu, N.; Luo, H.; Chen, Y.Y. Electronic and morphological dual modulation of colbat carbonate hydroxides by Mn doping towards highly efficient and stable bifunctional electrocatalysts for overall water splitting. J. Am. Chem. Sci. 2017, 24, 8320-8328. [CrossRef]

47. Chen, P.; Zhou, T.; Zhang, M.; Tong, Y.; Zhong, C.; Zhang, N. 3D nitrogen-anion-decorated nickel sulfides for highly efficient overall water splitting. Adv. Mater. 2017, 29, 1701584. [CrossRef] [PubMed]

48. Xue, Z.; Li, X.; Liu, Q.; Cai, M.; Liu, K.; Liu, M. Interfacial electronic structure modulation of NiTe nanoarrays with NiS nanodots facilitates electrocatalytic oxygen evolution. Adv. Mater. 2019, 31, 1900430. [CrossRef] [PubMed]

49. Niu, S.; Jiang, W.J.; Wei, Z.; Tang, T.; Ma, J.; Hu, J.S. Se-doping activates FeOOH for cost-effective and efficient electrochemical water oxidation. J. Am. Chem. Sci. 2019, 17, 7005-7013. [CrossRef]

50. Yu, M.; Wang, Z.; Liu, J.; Sun, F.; Yang, P.; Qiu, J. A hierarchically porous and hydrophilic 3D nickel-iron/mxene electrode for accelerating oxygen and hydrogen evolution at high current densities. Nano Energy 2019, 63, 103880. [CrossRef]

51. Senthil, R.D.; Lin, H.W.; Lu, S.Y. Synergistically well-mixed MOFs grown on nickel foam as highly efficient durable bifunctional electrocatalysts for overall water splitting at high current densities. Nano Energy 2019, 57, 1-13. [CrossRef]

52. Zhang, J.; Hu, Y.; Liu, D.; Yu, Y.; Zhang, B. Enhancing oxygen evolution reaction at high current densities on amorphous-like Ni-Fe-S ultrathin nanosheets via oxygen incorporation and electrochemical tuning. Adv. Sci. 2017, 4, 1600343. [CrossRef] [PubMed]

53. Zhang, H.; Li, X.; Hähnel, A.; Naumann, V.; Lin, C.; Azimi, S. Bifunctional heterostructure assembly of NiFe LDH nanosheets on NiCoP nanowires for highly efficient and stable overall water splitting. Adv. Funct. Materi. 2018, 28, 1706847. [CrossRef]

54. Tiwari, J.N.; Dang, N.K.; Sultan, S.; Thangavel, P.; Jeong, H.Y.; Kim, K.S. Multi-heteroatom-doped carbon from waste-yeast biomass for sustained water splitting. Nat. Sustain. 2020, 3, 556-563. [CrossRef]

55. Wu, F.; Guo, X.; Hao, G.; Hu, Y.; Jiang, W. Electrodeposition of sulfur-engineered amorphous nickel hydroxides on MIL-53(Fe) nanosheets to accelerate the oxygen evolution reaction. Nanoscale 2019, 11, 14785-14792. [CrossRef]

56. Xie, M.; Yang, L.; Ji, Y.; Wang, Z.; Ren, X.; Liu, Z. An amorphous Co-carbonate-hydroxide nanowire array for efficient and durable oxygen evolution reaction in carbonate electrolytes. Nanoscale 2017, 9, 16612-16615. [CrossRef] [PubMed]

57. Liang, C.; Zou, P.; Nairan, A.; Zhang, Y.; Liu, J.; Liu, K. Exceptional performance of hierarchical Ni-Fe oxyhydroxide@NiFe alloy nanowire array electrocatalysts for large current density water splitting. Energ. Environ. Sci. 2020, 13, 86-95. [CrossRef] 